Sharif University of Technology
Scientia Iranica
Transactions E: Industrial Engineering
hCIENTIA

\title{
An effective league championship algorithm for the stochastic multi-period portfolio optimization problem
}

\author{
A. Husseinzadeh Kashan*, M. Eyvazi, and A. Abbasi-Pooya \\ Faculty of Industrial and Systems Engineering, Tarbiat Modares University, Tehran, P.O. Box 14115-111, Iran.
}

Received 16 June 2017; received in revised form 6 August 2018; accepted 15 September 2018

\section{KEYWORDS}

Portfolio optimization; Single- and multiperiod models; League championship algorithm.

\begin{abstract}
The Multi-Period Portfolio Optimization (MPPO) models have been introduced to overcome the weaknesses of the single-period models via considering a dynamic optimization system. However, considering the nonlinear nature of the problem and rapid growth of the size complexity with increase in the number of periods and scenarios, this study is devoted to developing a novel League Championship Algorithm (LCA) to maximize the mean variance function of the portfolio subject to different constraints. A Vector AutoRegression (VAR) model was developed to estimate the return on risky assets in different time periods and to simulate different scenarios of the rate of return, accordingly. Besides, we proved a valid upper bound of the objective function based on the idea of using surrogate relaxation of constraints. Our computational results based on sample data collected from S\&P 500 and 10-year T. bond indices indicated that the quality of portfolios, in terms of the mean variance measure, obtained by LCA was 10 to 20 percent better than that by the commercial software. It seems promising that our method can be a suitable tool for solving a variety of portfolio optimization problems.
\end{abstract}

(C) 2020 Sharif University of Technology. All rights reserved.

\section{Introduction}

The problem of decision-making under uncertainty for choosing asset classes is one of the important topics in financial areas. Markowitz [1] was the first scholar who conducted research on portfolio optimization models. By combining optimization with probability theory, he modeled investment with uncertainty. Taking account of the return on investment as the average of returns and the risk of investment as the variance was the technique for mathematical modeling. Accordingly, risk is considered by calculating the variance in the mean variance models, as suggested by Yoshimoto [2],

\footnotetext{
*. Corresponding author. Tel.: +982182884398

E-mail addresses: a.kashan@modares.ac.ir (A.

Husseinzadeh Kashan); mohammad.eyvazi@modares.ac.ir

(M. Eyvazi); a.abbasipooya@modares.ac.ir (A.

Abbasi-Pooya)
}

doi: $10.24200 /$ sci. 2018.20995
Best and Hlouskova [3], Liu et al. [4], and Corazza and Favaretto [5], to mention a few examples. It is worth mentioning that the above-mentioned studies work on the assumption of single-period portfolio optimization, which does not sufficiently model the real-world conditions in investment. Since market conditions change over time and investors decide on their wealth accordingly, single-period models need to be extended to multi-period ones. In other words, wealth allocation to asset classes in inconsistent financial markets with high diversity requires employing multi-period stochastic optimization models.

Multi-period models for portfolio optimization adequately take account of uncertainty for effective parameters like return on assets class and external cash flow [6]. This is one of the important advantages of Multi-Period Portfolio Optimization (MPPO) models over single-period ones. The goal of the MPPO is to minimize risk and maximize return. While maximizing return on investments in portfolios intervenes 
in making decisions on the percentage of the overall portfolio value allocated to each portfolio component, minimizing the risk of different investment instruments is also important at the same time to create or maintain portfolios with the specified risk-return characteristics. The MPPO technique demonstrates the dynamic aspect of models for achieving optimal solution and efficient frontier $[6,7]$.

\section{Literature review}

As previously implied, single-period models form the basis for multi-period ones. A recent study by Ertenlice and Kalayci [8] has investigated the use of swarm intelligence for portfolio optimization in single- and multi-period optimization cases. As an example of the single-period models, Yoshimoto [2] addressed the portfolio optimization considering transaction cost and its effect on the portfolio. Best and Hlouskova [3] proposed a closed-form solution to the portfolio selection problem for uncorrelated and bounded assets. Deng et al. [9] developed a Particle Swarm Optimization (PSO) algorithm for Cardinality-Constrained Portfolio Optimization (CCPO) problem, which outperformed Genetic Algorithm (GA), simulated annealing, and Tabu search. Woodside-Oriakhi et al. [10] presented metaheuristics based upon GA, simulated annealing, and Tabu search for Markovitz's mean variance model considering the discrete constraints of buy-in thresholds and cardinality. A greedy randomized adaptive search procedure has been developed in [11] for CCPO. An artificial bee colony algorithm is also proposed in [12] for CCPO.

There are a large number of models proposed for MPPO. For instance, Bradley and Crane [13] introduced a multi-period bond portfolio model and a new approach to efficiently solving problems with decomposition algorithm of mathematical programming. A stochastic linear programming formulation of the short-term financial planning problem for a firm was modeled under uncertainty by Kallberg and Ziemba [14]. Stochastic network optimization models were described for investment planning under uncertainty and the performance of the models in simulations based on historical data was investigated by Mulvey and Vladimirou [15]. Furthermore, a multiperiod mean variance portfolio selection model with bankruptcy constraint under the framework of probability theory was developed for a stochastic market by Wei and Ye [16]. Bertsimas and Pachamanova [17] presented different robust formulations for the MPPO problems and considered transaction cost in their models. Furthermore, they compared the performance of robust formulations with the performance of the traditional mean variance formulation. Çakmak and Özekici [18] proposed an MPPO model that rebalanced the portfolio according to time horizon and the changes of market parameters. $\mathrm{Li}$ and $\mathrm{Ng}$ [19] formulated an analytical expression for the multi-period mean variance efficient frontier. They also introduced an algorithm for finding the optimal portfolio policy. The bankruptcy approach was used for executing optimal portfolio policy by Zhu et al. [20]. Using the downside risk criterion, Pinar [21] revisited the multi-period portfolio model. The multi-period mean-semivarianceentropy model based on possibility theory was formulated by Zhang et al. [22]. Fang et al. [23] took a fuzzy set based theory approach to the MPPO problem. The multi-period portfolio model with different rates was also introduced for borrowing and lending in fuzzy environment by Sadjadi et al. [24]. Zhang and Zhang [25] considered a multi-period fuzzy portfolio selection problem with absolute deviation as the risk control of portfolio. The model included transaction cost, borrowing constraints, threshold constraints, and cardinality constraints. Additionally, discrete approximate iteration method was applied to solving the optimal portfolio. Yao et al. [26] presented multiperiod mean variance portfolio selection problem with a stochastic interest rate in which the movement of the interest rate followed the Vasicek model. In addition, dynamic programming approach and Lagrange duality theory were used to overcome increasing complexity.

Given the fact that the MPPO problem is a nonlinear complex problem with many local optima and time is a constraint for financial problems, heuristic methods seem to be good tools for achieving a trade-off between the quality and the computational time. Heuristic methods such as Tabu search [27,28], GA [29], and PSO [30] are only some examples. Yan et al [31] introduced a class of multi-period semivariance models and applied a novel hybrid GA and PSO algorithm to solving this model type. Zhang et al. [32] used possibilistic mean variance approach to extending multi-period fuzzy portfolio selection problems. Moreover, they formulated a PSO algorithm for these portfolio selection problems. Liu et al. [33] investigated a multi-period portfolio selection problem with bankruptcy control and affine recourse in fuzzy investment environment and proposed a credibilistic MPPO model. Furthermore, a hybrid PSO algorithm was used for solving the model. Liu et al. [34] presented a robust multi-period portfolio model based on the robust theory and prospect theory. To solve the model, an improved PSO algorithm was developed. Wang et al. [35] studied MPPO problem with returns considered as fuzzy random variables and proposed a fuzzy simulation-based PSO algorithm for solving the problem. Li et al. [36] considered an uncertain multiperiod portfolio selection problem with the influence of transaction cost and bankruptcy. They solved the problem using GA with penalty function. Discounted 
transaction costs in a fuzzy environment were considered in the multi-period portfolio selection problem. After transforming the problem into a single-objective equivalent, a differential evolution algorithm was used to solve it.

This paper considers the stochastic optimization model for multi-period asset class portfolio problem. Asset class includes cash, stock, bond, and real state. Sample data are collected from S\&P 500 and 10-year $\mathrm{T}$. bond indices. To extract scenarios from historical data, a Vector Auto-Regression (VAR) model is first developed to predict the return on risky assets. An upper bound for the optimal value of the mean variance objective function is proposed by surrogate relaxation of the constraint via aggregation over all scenarios. We prove that the bound is valid. To solve the problem instances of MPPO, a metaheuristic algorithm is developed based on the League Championship Algorithm (LCA) and a penalty based method is used to handle entropy constraints. Our computations reveal that the proposed methodology has a considerable impact on the quality of the constituted portfolios by improving the mean variance objective function from 10 to 20 percent in comparison with the results provided by a commercial solver.

Therefore, the contribution of this paper is threefold. First, an MPPO problem is formulated considering diversification in portfolio and uncertainty about returns on risky assets. To diversify portfolio construction, the Shannon entropy measure is used as an optimization constraint. To cope with the uncertainty, a scenario-based approach is followed and a VAR model is developed to predict and include the return on risky assets in the optimization model. Via adopting a surrogate relaxation technique and mathematical properties, an upper bound of the optimal objective function value is also provided. To cope with the nonlinearity of the problem and to solve it for larger complex instances, an effective LCA is proposed. Statistical results show that the LCA significantly improves the results provided by the LINGO commercial solver.

The remainder of the paper is organized as follows. In Section 2, we formulate an MPPO problem with investment rebalancing in several discrete time points (periods). Since there is uncertainty in the MPPO problem, we also estimate return rate on risky assets by the VAR model based on scenario tree in Section 3. Section 4 is devoted to designing a method to obtain an upper bound for the optimal value of the objective function in our problem. In Section 5, we give a brief introduction to LCA and apply it to the MPPO problem in hand. Section 6 presents computational experiments and the results of solving the problem with LINGO/Quadratic Solver. Also, the proposed algorithm is given in this section along with the analysis of the gap between the results of the Quadratic Solver and LCA. Finally, the paper is concluded in Section 7.

\section{Multi-Period Portfolio Optimization (MPPO) problem}

The MPPO problem expresses stochastic optimization with investment rebalancing in several discrete time points the lengths between which are called periods. In the MPPO problem, we must specify planning horizon and asset investment classes. Planning horizon covers $\tau$ time periods introduced by $T=\{0,1, \cdots, \tau\} . T=0$ represents the present position and $T=\tau$ is the planning horizon. Present position is considered as the starting point for scenario generation. Decisions are made at the end of each time period. Asset investment classes, introduced by the set $A=\{1,2, \cdots, E\}$, include broad investment classes, e.g., stocks, bonds, real state, and cash. Because asset classes must track the market, in our case, S\&P 500 index is representative of stock and 10-year T. bond is for bond. Uncertainty is modeled through a finite number of scenarios each representing a possible realization of all uncertain parameters. The set of all scenarios is represented by $S$. We will show how different scenarios can be realized using a VAR model. The mathematical model of the MPPO problem can be presented as follows:

$$
\text { Maximize } z=\nu \operatorname{Mean}_{s}\left(w_{\tau}\right)-(1-\nu) \operatorname{Var}_{s}\left(w_{\tau}\right) \text {, }
$$

s.t.:

$$
\begin{aligned}
& \sum_{n \in A} x_{n, 0}^{s}=w_{0} \quad \forall s \in S, \\
& \sum_{n \in A} x_{n, t}^{s}=w_{t}^{s} \quad \forall s \in S, \quad t \in T, \\
& v_{n, t}^{s}=r_{n, t-1}^{s} x_{n, t-1}^{s} \quad \forall s \in S, \quad t \in T, \quad n \in A, \\
& x_{n, t}^{s}=v_{n, t}^{s}+c_{n, t}^{s}\left(1-\gamma_{n, t}\right)-y_{n, t}^{s} \\
& \forall s \in S, \quad t \in T, \quad n \in A, \quad n \neq 1, \\
& x_{1, t}^{s}=v_{1, t}^{s}+\sum_{n \in A, n \neq 1} y_{n, t}^{s}\left(1-\gamma_{n, t}\right)-\sum_{n \in A, n \neq 1} c_{n, t}^{s}, \\
& \forall s \in S, \quad t \in T, \quad n \in A, \quad n \in A, \\
& -\sum_{n \in A} \frac{x_{n, t}^{s}}{w_{t}^{s}} \ln \frac{x_{n, t}^{s} \geq e_{t}}{w_{t}^{s}} \quad \forall s \in S, \quad t \in T,
\end{aligned}
$$

The set of parameters and decision variables used in the mathematical model of the MPPO is defined as follows: 


\section{Parameters}

$r_{n, t}^{s}=1+l_{n, t}^{s}$ Where $l_{n, t}^{s}$ is the rate of return on asset $n$ in time period $t$ under scenario $s$

$w_{0} \quad$ Initial wealth at time 0

$\gamma_{n, t} \quad$ Transaction costs incurred in rebalancing risky asset $n$ at the beginning of time period $t$

$e_{t} \quad$ Minimum limit for diversification constraint at time $t$

\section{Decision variables}

$x_{n, t}^{s} \quad$ Amount of money for asset $n$ in time period $t$ under scenario $s$ after rebalancing

$v_{n, t}^{s} \quad$ Amount of money in asset $n$ at the end of period $t$ under scenario $s$ before rebalancing

$w_{t}^{s} \quad$ Wealth at the beginning of time period $t$ under scenario $s$

$c_{n, t}^{s} \quad$ Amount of asset $n$ purchased for rebalancing at time $t$ under scenario $s$

$y_{n, t}^{s} \quad$ Amount of asset $n$ sold for rebalancing in time period $t$ under scenario $s$

The objective function of Eq. (1) is in the form of mean variance. In this function, $\operatorname{Mean}_{s}\left(w_{\tau}\right)$ is the mean and $\operatorname{Var}_{s}\left(w_{\tau}\right)$ is the variance of the total wealth across all scenarios in the final period, namely $\tau$. Parameter $\nu$ indicates the relative significance of mean compared to the variance component. There are other objective functions such as mean variance skewness and Von Neumann-Morgenstern expected utility of wealth that can also be used.

Eq. (2) states that total assets of the investor in time 0 are equal to the wealth at the beginning. Eq. (3) guarantees that the total assets of investor in time $t$ are equal to the wealth at the beginning of time period $t$ under scenario $s$. Eq. (4) updates the wealth accumulated at the end of period $t$ under scenario $s$ for each asset $n$ before rebalancing. Eq. (5) depicts the flow balance for all assets in each time period and scenario. Eq. (6) calculates the amount of money invested in cash in time period $t$ under scenario $s$ after rebalancing. Finally, Relation (7) represents the entropy constraints used to diversify the portfolio.

\section{Scenario generation using Vector Auto-Regression (VAR) model}

Uncertainty in MPPO problem is modeled by a scenario tree. The important parameter that should be estimated for the next periods is the return rate on risky assets. There are two general methods for modeling future asset returns [37]. The first one is based on the economic parameters including interest rate, inflation, and market index. This method is called rational expectations and employs conceptual macroeconomic models. For example, market index can be used to generate scenario for the next stock return [30]. The second method, which is called adaptive expectations, depends only on the historical data of the explanatory variables. This paper does not focus on the evaluation of these methods. Considering the fact that modeling future events based on macroeconomic models is difficult, the method employed in this paper is based on the second approach.

A VAR model is used to construct scenario tree. Let $S$ represent the scenario set that is defined by $s \in S:=\{1,2, \cdots, S\}$ and each scenario have a probability that is denoted by $\pi_{s}$. Scenario generation can have different models. For instance, a scenario may be generated by a binary tree that bifurcates in two branches from each node. The tree that is used in our model includes different paths, as depicted in Figure 1, with 6 scenarios and 6 periods. follows:

The general equation of the VAR model is as

$$
r_{t}=H+E_{1} r_{t-1}+E_{2} r_{t-2}+\cdots+E_{q} r_{t-q}+k_{t}
$$

We have:

$$
E\left(r_{t} \mid f_{t-1}\right)=H+E_{1} r_{t-1}+E_{2} r_{t-2}+\cdots+E_{q} r_{t-q},
$$

in which $r_{t}$ is the vector of rate of returns on the risky asset group. $k_{t}$ is the vector of random disturbances with zero mean and a known variance, which is distributed independently in the time horizon. Also, $q$ is the number of lags used in the model. Furthermore, $E_{1}, \cdots, E_{q}$ are time-independent constant matrices predicted through statistical methods such as maximum likelihood estimation and $H$ is the vector of intercepts from auto-regression. Rates of the return on risky assets such as stocks and bonds are modeled based on past returns. Residuals play the main role in modeling the rate of return based on past data, because they are used to model the disturbances of return in time horizon. VAR models for stock and bond are estimated using the data from 2001 to 2013 obtained from Yahoo Finance as:

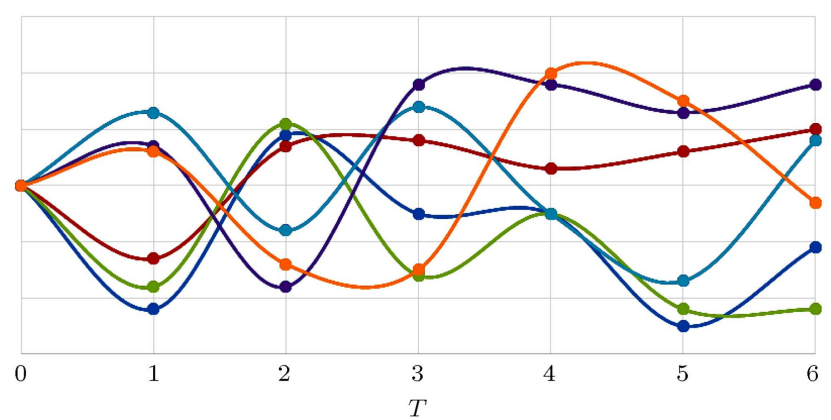

Figure 1. Scenario generation for 6 periods and 6 paths. 


$$
\begin{aligned}
r_{2, t}= & 0.01133+0.1015 r_{2, t-1}^{s}-0.25137 r_{2, t-2}^{s} \\
& +0.74185 r_{3, t-1}^{s}+0.35271 r_{3, t-2}^{s}+z_{t}^{s}, \\
r_{3, t}^{s}= & 0.12897+0.27529 r_{3, t-1}^{s}-0.76651 r_{3, t-2}^{s} \\
& +0.06076 r_{2, t-1}^{s}+0.17099 r_{2, t-2}^{s}+u_{t}^{s},
\end{aligned}
$$

where $r_{2, t}^{s}$ is the rate of stock return and $r_{3, t}^{s}$ is the rate of bond return under scenario $s$. Rate of cash return for all of the periods is constant and equal to 0.12 , and the models are run for 4 and 7 periods. The autocorrelation of residuals is checked for the assumption of the model. The first lag coefficients are statistically significant at the level of $10 \%$. Uncertainty is characterized by $z_{t}^{s}$ for stock and $u_{t}^{s}$ for bond. These random numbers are generated using a normal distribution, since the distribution of the residuals is normal. Eqs. (10) and (11) are used in scenario generation with 2, 5, 10, 20, and 50 paths for 4 and 7 periods. Each path from $T=0$ to $T=\tau$ represents a scenario. Tables 1 and 2 show some realization of the scenarios generated by the VAR model, specifically the rates of return on two risky assets under 10 scenarios and 7 periods.

\section{An upper bound for the optimal value of the mean variance of the MPPO problem}

The purpose of this section is to provide a method to obtain an upper bound for the optimal value of the mean variance (objective function) in the MPPO problem. The idea for the proposed upper bound method relies on the concept of surrogate constraints. One way to relax tight constraints is to integrate them into a set of constraints that are weaker. The result is a linear programming problem that is called the relaxed problem with surrogate/substitute constraints.

Starting with Eqs. (2)-(5) and summing up all scenarios, then dividing by the number of scenarios (i.e., $|S|$ ), we have:

$$
\begin{array}{cc}
\sum_{s} \sum_{n} x_{n, t}^{s} /|S|=w_{0} & \forall t, \\
\sum_{s} \sum_{n} x_{n, t}^{s} /|S|=\sum_{s} w_{t}^{s} /|S| \quad \forall t, & \\
\sum_{s} x_{n, t}^{s} /|S| & =\sum_{s} r_{n, t-1}^{s} x_{n, t-1}^{s} /|S| \\
& +\sum_{s} c_{n, t}^{s}\left(1-\gamma_{n, t}^{s}\right) /|S|-\sum_{s} y_{n, t}^{s} /|S| \\
\forall n, t .
\end{array}
$$

\begin{tabular}{|c|c|c|c|c|c|c|c|c|c|c|c|}
\hline & & \multicolumn{10}{|c|}{ Scenario } \\
\hline & & 1 & 2 & 3 & 4 & 5 & 6 & 7 & 8 & 9 & 10 \\
\hline \multirow{7}{*}{$\begin{array}{l}\overrightarrow{0} \\
\stackrel{0}{\dot{0}} \\
\mathfrak{u}_{1}\end{array}$} & 2013 & 1.322 & 1.322 & 1.322 & 1.322 & 1.322 & 1.322 & 1.322 & 1.322 & 1.322 & 1.322 \\
\hline & 2014 & 1.078 & 0.991 & 1.060 & 1.028 & 1.101 & 1.061 & 1.076 & 1.033 & 0.989 & 1.124 \\
\hline & 2015 & 1.037 & 1.012 & 1.227 & 1.218 & 1.085 & 1.115 & 1.016 & 1.160 & 1.186 & 1.119 \\
\hline & 2016 & 1.145 & 1.273 & 1.190 & 1.249 & 1.235 & 1.262 & 1.273 & 1.197 & 1.216 & 1.211 \\
\hline & 2017 & 1.105 & 1.266 & 0.997 & 1.054 & 1.150 & 1.155 & 1.222 & 1.053 & 1.187 & 1.089 \\
\hline & 2018 & 1.131 & 1.193 & 1.100 & 1.141 & 1.063 & 1.107 & 1.191 & 1.117 & 1.198 & 1.055 \\
\hline & 2019 & 1.254 & 1.182 & 1.258 & 1.305 & 1.288 & 1.087 & 1.107 & 1.274 & 1.085 & 1.270 \\
\hline
\end{tabular}

\begin{tabular}{|c|c|c|c|c|c|c|c|c|c|c|c|}
\hline & & \multicolumn{10}{|c|}{ Scenario } \\
\hline & & 1 & 2 & 3 & 4 & 5 & 6 & 7 & 8 & 9 & 10 \\
\hline \multirow{7}{*}{ 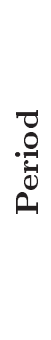 } & 2013 & 0.909 & 0.909 & 0.909 & 0.909 & 0.909 & 0.909 & 0.909 & 0.909 & 0.909 & 0.909 \\
\hline & 2014 & 1.162 & 1.140 & 1.188 & 1.193 & 1.173 & 1.181 & 1.139 & 1.174 & 1.146 & 1.131 \\
\hline & 2015 & 1.113 & 1.157 & 1.145 & 1.142 & 1.132 & 1.133 & 1.170 & 1.151 & 1.121 & 1.188 \\
\hline & 2016 & 1.010 & 1.019 & 0.963 & 0.973 & 0.987 & 1.023 & 1.015 & 0.976 & 1.050 & 1.004 \\
\hline & 2017 & 1.053 & 1.094 & 1.073 & 1.061 & 1.058 & 1.067 & 1.066 & 1.077 & 1.059 & 1.035 \\
\hline & 2018 & 1.161 & 1.077 & 1.167 & 1.158 & 1.147 & 1.101 & 1.118 & 1.148 & 1.106 & 1.100 \\
\hline & 2019 & 1.088 & 1.061 & 1.072 & 1.058 & 1.069 & 1.093 & 1.075 & 1.033 & 1.080 & 1.119 \\
\hline
\end{tabular}

Let us define the following equalities:

$$
\sum_{s} x_{n, 0}^{s} /|S|=\bar{x}_{n, 0}, \quad \sum_{s} c_{n, t}^{s} /|S|=\bar{c}_{n, t},
$$

Table 1. Sample scenarios for the stock rate of return (10 scenarios, 7 periods).

Table 2. Sample scenarios for the bond rate of return (10 scenarios, 7 periods). 


$$
\begin{aligned}
& \sum_{s} x_{n, t}^{s} /|S|=\bar{x}_{n, t}, \quad \sum_{s} w_{t}^{s} /|S|=\bar{w}_{t}, \\
& \sum_{s} y_{n, t}^{s} /|S|=\bar{y}_{n, t} .
\end{aligned}
$$

As a result, we can rewrite Eqs. (12)-(14) as follows:

$$
\begin{aligned}
& \sum_{n} \bar{x}_{n, 0}=w_{0} \\
& \sum_{n} \bar{x}_{n, t}=w_{t} \quad \forall t \\
& \bar{x}_{n, t}=\sum_{s} r_{n, t-1}^{s} x_{n, t-1}^{s} /|S|+\bar{c}_{n, t}\left(1-\gamma_{n, t}\right)-\bar{y}_{n, t} \\
& \forall n, t .
\end{aligned}
$$

Lemma 1. Given $\sum_{s} r_{n, t-1}^{s} x_{n, t-1}^{s} /|S|=\bar{r}_{n, t-1}$, the following inequality is valid.

$$
\sum_{s} r_{n, t-1}^{s} x_{n, t-1}^{s} /|S| \leq \sqrt{\bar{r}_{n, t-1}^{2}} \sqrt{\bar{x}_{n, t-1}^{2}}
$$

Proof. Based on the Cauchy-Schwarz inequality, we have $\sum_{i} x_{i} y_{i} \leq \sqrt{x_{i}^{2}} \sqrt{y_{i}^{2}}$. Starting from the first expression in the right side of Eq. (17), we have:

$$
\begin{aligned}
& \sum_{s} r_{n, t-1}^{s} x_{n, t-1}^{s} \leq \sqrt{\sum_{s}\left(r_{n, t-1}^{2}\right)^{2}} \sqrt{\sum_{s}\left(x_{n, t-1}^{2}\right)^{2}} \\
& \quad \Rightarrow \sum_{s} r_{n, t-1}^{s} x_{n, t-1}^{s} /|S| \\
& \quad \leq \sqrt{\sum_{s}\left(r_{n, t-1}^{2}\right)^{2} /|S|} \sqrt{\sum_{s}\left(x_{n, t-1}^{2}\right)^{2} /|S|} \\
& \quad \leq \sqrt{\overline{r_{n, t-1}^{2}}} \sqrt{\overline{x_{n, t-1}^{2}}} .
\end{aligned}
$$

\section{Lemma 2.}

$$
\sqrt{\overline{r_{n, t-1}^{2}}} \sqrt{\overline{x_{n, t-1}^{2}}} \leq \sqrt{\left(1+\frac{|S|^{2}}{9}\right)} \bar{r}_{n, t-1} \bar{x}_{n, t-1}
$$

Proof. It has been proved by Jacobson [38] that for $x_{i}>0$, the inequality $\operatorname{Var}\left(x_{i}\right) \leq x_{\max }^{2} / 9$ holds. Such an inequality ensures that $\overline{x^{2}} \leq \bar{x}^{2}+x_{\max }^{2} / 9$. Furthermore, it has been accepted that $x_{\max } \leq N \bar{x}$, where $N$ is the number of observations. Therefore, we can write:

$$
\overline{x_{n, t-1}^{2}} \leq \bar{x}_{n, t-1}^{2}+\frac{|S|^{2} \bar{x}_{n, t-1}^{2}}{9}
$$

and:

$$
\overline{r_{n, t-1}^{2}} \leq \bar{r}_{n, t-1}^{2}+\frac{|S|^{2} \bar{r}_{n, t-1}^{2}}{9} .
$$

Now, the required result is attainable.

Thus, the final form of Eq. (17) is reduced to Inequality (19) as follows:

$$
\begin{aligned}
\bar{x}_{n, t} \leq & \sqrt{\left(1+\frac{|S|^{2}}{9}\right)} \bar{r}_{n, t-1} \bar{x}_{n, t-1}+\bar{c}_{n, t}\left(1-\gamma_{n, t}\right) \\
& -\bar{y}_{n, t} \quad \forall t, n, n \neq 1 .
\end{aligned}
$$

In a similar way, we can treat Eq. (6) to obtain the following.

$$
\begin{aligned}
\bar{x}_{1, t} \leq & \sqrt{\left(1+\frac{|S|^{2}}{9}\right)} \bar{r}_{1, t-1} \bar{x}_{1, t-1} \\
& +\sum_{n, n \neq 1} \bar{y}_{n, t}\left(1-\gamma_{n, t}\right)-\sum_{n, n \neq 1} \bar{c}_{n, t} \quad \forall t .
\end{aligned}
$$

Now, we obtain the objective function. Given that $\bar{w}_{\tau}=\operatorname{Mean}_{s}\left(w_{\tau}^{s}\right)$ is an upper bound for the objective function, the optimal value of the objective function of the following linear programming problem (Eqs. (21)(25)) gives an upper bound for the optimal value of the mean variance function.

$$
\begin{aligned}
& \max z=v \bar{w}_{\tau}, \\
& \sum_{n} \bar{x}_{n, 0}=w_{0}, \\
& \sum_{n} \bar{x}_{n, t}=w_{t} \quad \forall t \\
& \bar{x}_{n, t} \leq \sqrt{\left(1+\frac{|S|^{2}}{9}\right)} \bar{r}_{n, t-1} \bar{x}_{n, t-1}+\bar{c}_{n, t}\left(1-\gamma_{n, t}\right) \\
& \quad-\bar{y}_{n, t} \forall t, n \neq 1, \\
& \bar{x}_{n, t} \leq \sqrt{\left(1+\frac{|S|^{2}}{9}\right)} \bar{r}_{n, t-1} \bar{x}_{n, t-1} \\
& \quad+\sum_{n \neq 1} \bar{y}_{n, t}\left(1-\gamma_{n, t}\right)-\sum_{n \neq 1} \bar{c}_{n, t} \quad \forall t .
\end{aligned}
$$

\section{A League Championship Algorithm (LCA) applied to the MPPO problem}

This section is devoted to introducing the LCA along with its application to the problem of MPPO. There are some features of LCA that make it an appropriate choice for the problem in this study. First, from a theoretical perspective, the concept of LCA is easily understandable and implementable. The algorithm 
also has few parameters, which is a feature that make its use more desirable. On the other hand, from the practical perspective, the constrained version of LCA has been evaluated in terms of its performance for 24 benchmark problems in [39]. Seven problems were quadratic and LCA demonstrated outstanding performance compared to other algorithms. Therefore, the performance of this newly proposed algorithm is worth investigating for the MPPO problem, which is of quadratic nature.

\section{1. $L C A$}

The LCA is a population-based global optimization algorithm proposed by Husseinzadeh Kashan [39-43], which was inspired by sports leagues. In this section, a brief introduction to LCA is presented along with the required adjustments to make it suitable for solving the MPPO problem.

The mapping between LCA and optimization problem elements is as follows: Weeks represent iterations, the playing strength is expressed as fitness value, team formation represents solution, changes in its formation are like the generation of a new solution, and the number of seasons represents the stopping condition

\subsubsection{Rules of $L C A$}

There are some idealized rules of the regular championship environment to imagine the artificial championship modeled by LCA. These rules are:

1. The result of a match is not predictable;

2. A team with higher playing strength has more likelihood of winning against the other team;

3. From the viewpoints of both teams, the probability that they would beat the rival is assumed the same;

4. The result of a match is only win or loss;

5. Teams only concentrate on the next match instead of all future matches;

6. Any weakness in one team is the lack of a particular strength in that team.

In LCA, team formation (solution) can be represented by a vector of size $1 \times n$ ( $n$ is the number of variables) of real numbers. Each element is related to one of the players and shows the value of the variable of the problem. Let $f\left(X=\left(x_{1}, x_{2}, \cdots, x_{n}\right)\right)$ be an $n$ variable numerical function that should be minimized over the decision space specified as a subset of $R^{n}$. Team formation (a potential solution) for team $i$ in week $t$ can be represented by $X_{i}^{t}=\left(x_{i 1}^{t}, x_{i 2}^{t}, \cdots, x_{i n}^{t}\right)$ with $f\left(X_{i}^{t}\right)$ stating the value of the function resulting from $X_{i}^{t}$.

\subsubsection{Creating the league schedule}

The first step is to schedule the games in each season. In this paper, a single round-robin schedule is used. A

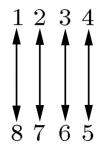

(a)

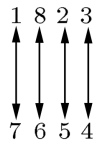

(b)

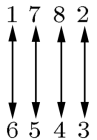

(c)

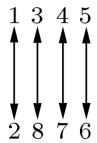

(d)
Figure 2. A sample single round-robin scheduling algorithm.

sample of league scheduling is depicted in Figure 2 for a sports league with 8 teams. In the first week (a), 1 plays against 8,2 plays against 7 , and so on. In the next weeks (b), one team is fixed and other teams are rotated clockwise to make a complete schedule. Assuming that a sports league has $L$ teams, the single round-robin tournament needs $L \times(L-1) / 2$ matches, where $(L-1)$ is the number of matches, and $L / 2$ matches will be held in parallel. For a sports league with $S$ seasons, there are $S \times(L-1)$ weeks of matches.

\subsubsection{Deciding the outcome of a match}

To specify the winner and the loser, tournament selection can be used. Based on the idealized rule 1, we may write:

$$
\frac{f\left(X_{i}^{t}\right)-f^{*}}{f\left(X_{j}^{t}\right)-f^{*}}=\frac{p_{j}^{t}}{p_{i}^{t}},
$$

where $X_{i}^{t}\left(X_{j}^{t}\right)$ is the formation of team $i$ (team $j$ ) in week $t, f\left(X_{i}^{t}\right)\left(f\left(X_{j}^{t}\right)\right)$ is the playing strength of team $i$ (team $j$ ), $p_{i}^{t}\left(p_{j}^{t}\right)$ is the probability that team $i$ (team $j$ ) would beat team $j$ (team $i$ ) in week $t$, and $f^{*}$ is a bound for the optimal value of the objective function.

Additionally, from idealized rule 3, we have:

$$
p_{i}^{t}+p_{j}^{t}=1
$$

From Eqs. (26) and (27), we obtain:

$$
p_{i}^{t}=\frac{f\left(X_{j}^{t}\right)-f^{*}}{f\left(X_{j}^{t}\right)+f\left(X_{i}^{t}\right)-2 f^{*}} .
$$

In order to decide the winner and the loser, a uniformly distributed random number in $[0,1]$ is generated. Two cases can occur:

1. If this random number is less than or equal to $p_{i}^{t}$, team $i$ wins and team $j$ loses;

2. If this random number is greater than $p_{i}^{t}$, team $j$ wins and team $i$ loses.

\subsubsection{Setting up new team formation}

In each iteration, there should be a mechanism to move a set of solutions (population) by changing the configuration of each solution (team). Assessment of weaknesses and strengths of a team is the first step for setting up new formation. Furthermore, changes in the formation of each team are based on the result of the team which will be encountered in week $t+1$. This task 
is conducted based on SWOT analysis. Let us define the following three indices:

$l \quad$ The team that will play against team $i$ $(i=1, \cdots, L)$ in week $t+1$

$j \quad$ The team that played against team $i$ $(i=1, \cdots, L)$ in week $t$

$k \quad$ The team that played against team $l$ in week $t$

The SWOT analysis is conducted according to the SWOT matrix presented in Figure 3. In order to determine the formation of team $i$ for playing against team $l$, if both $i$ and $l$ have won their previous matches, the S/T strategy (the first column in Figure 3) for team $i$ is to focus on its own strengths (or weaknesses of $j$ ) and strengths of $l$ (or weaknesses of $k$ ). Other cases can be interpreted similarly.

Based on the strategy adopted, we may write the equation for updating the solution. $X_{k}^{t}-X_{i}^{t}$ is defined as the difference between the arrangements of team $i$ and team $k$ focusing on the strengths of team $k$, while $X_{i}^{t}-X_{k}^{t}$ represents focusing on the weaknesses of team $k$. Knowing that each team, such as $i$, plays based on its best formation $B_{i}^{t}=\left(b_{i 1}^{t}, b_{i 2}^{t}, \cdots, b_{i n}^{t}\right)$ and being aware of the results of match analysis, we may write 4 strategies for new team formation:

1. If $i$ has won and $l$ has also won, then the new formation is generated by:

$$
\begin{aligned}
x_{i d}^{t+1}= & b_{i d}^{t}+y_{i d}^{t}\left(w_{1} r_{1 i d}\left(x_{i d}^{t}-x_{k d}^{t}\right)\right. \\
& \left.+w_{1} r_{2 i d}\left(x_{i d}^{t}-x_{j d}^{t}\right)\right) \quad \forall d=1, \cdots, n .
\end{aligned}
$$

2. If $i$ has won and $l$ has lost, then the new formation is generated by:

$$
\begin{aligned}
x_{i d}^{t+1}= & b_{i d}^{t}+y_{i d}^{t}\left(w_{2} r_{1 i d}\left(x_{k d}^{t}-x_{i d}^{t}\right)\right. \\
& \left.+w_{1} r_{2 i d}\left(x_{i d}^{t}-x_{j d}^{t}\right)\right) \quad \forall d=1, \cdots, n .
\end{aligned}
$$

3. If $i$ has lost and $l$ has won, then the new formation is generated by:

$$
\begin{aligned}
x_{i d}^{t+1}= & b_{i d}^{t}+y_{i d}^{t}\left(w_{1} r_{1 i d}\left(x_{i d}^{t}-x_{k d}^{t}\right)\right. \\
& \left.+w_{2} r_{2 i d}\left(x_{j d}^{t}-x_{i d}^{t}\right)\right) \quad \forall d=1, \cdots, n .
\end{aligned}
$$

4. If $i$ has lost and $l$ has also lost, then the new formation is generated by:

$$
\begin{aligned}
x_{i d}^{t+1}= & b_{i d}^{t}+y_{i d}^{t}\left(w_{2} r_{1 i d}\left(x_{k d}^{t}-x_{i d}^{t}\right)\right. \\
& \left.+w_{2} r_{2 i d}\left(x_{j d}^{t}-x_{i d}^{t}\right)\right) \quad \forall d=1, \cdots, n .
\end{aligned}
$$

In the above equations, $d$ is the dimension index; $r_{1 i d}$ and $r_{2 i d}$ are uniform random numbers in $[0,1]$; and $w_{1}$ and $w_{2}$ are coefficients used to scale the contributions of "retreat" and "approach" components, respectively. Also, in Eqs. (29) to (32), $y_{i d}^{t}$ is a binary change variable, which indicates whether $x_{i d}^{t+1}$ differs from $b_{i d}^{t}$ or not. Only $y_{i d}^{t}=1$ allows for difference.

Based on the above-mentioned concepts, the flowchart of LCA is depicted in Figure 4. The first step is to initialize control parameters and a random population of individuals (teams). Then, a league schedule is generated based on single roundrobin algorithm. The winning and losing teams of each match are determined through the tournament selection presented in Section 6.1.3. The algorithm then moves to the next set of solutions by using the match analysis of SWOT matrix. This procedure is continued until a stopping criterion is met.

\begin{tabular}{|c|c|c|c|c|}
\hline & $\begin{array}{l}\text { Adopt } S / T \text { strategy } \\
i \text { won, } \\
l \text { won. } \\
\text { Focus on } \ldots\end{array}$ & $\begin{array}{l}\text { Adopt } S / O \text { strategy } \\
i \text { won, } \\
l \text { lost } \\
\text { Focus on } \ldots\end{array}$ & $\begin{array}{l}\text { Adopt } W / T \text { strategy } \\
i \text { lost } \\
l \text { won, } \\
\text { Focus on } \ldots\end{array}$ & $\begin{array}{l}\text { Adopt } W / O \text { strategy } \\
i \text { lost } \\
l \text { lost. } \\
\text { Focus on } \ldots\end{array}$ \\
\hline$S$ & $\begin{array}{c}\text { Own strengths } \\
\text { (or weaknesses of } j \text { ) }\end{array}$ & $\begin{array}{c}\text { Own strengths } \\
\text { (or weaknesses of } j \text { ) }\end{array}$ & - & - \\
\hline$W$ & - & - & $\begin{array}{l}\text { Own weaknesses } \\
\text { (or strengths of } j \text { ) }\end{array}$ & $\begin{array}{l}\text { Own weaknesses } \\
\text { (or strengths of } j \text { ) }\end{array}$ \\
\hline$O$ & - & $\begin{array}{l}\text { Weakness's of } l \\
\text { (or strengths of } k \text { ) }\end{array}$ & - & $\begin{array}{c}\text { Weakness's of } l \\
\text { (or strengths of } k \text { ) }\end{array}$ \\
\hline$T$ & $\begin{array}{c}\text { Strengths of } l \\
\text { (or weaknesses of } k \text { ) }\end{array}$ & - & $\begin{array}{c}\text { Strengths of } l \\
\text { (or weaknesses of } k \text { ) }\end{array}$ & - \\
\hline
\end{tabular}

\subsection{Application of LCA to MPPO problem}

When LCA is used to solve the mathematical model (MPPO model), the objective function must be defined and solution represented first. In this study, we use the classical return-risk function as the objective function. Due to the uncertain nature of the multiperiod problem, we need to form a scenario tree. After

Figure 3. SWOT matrix for setting up a new formation. 


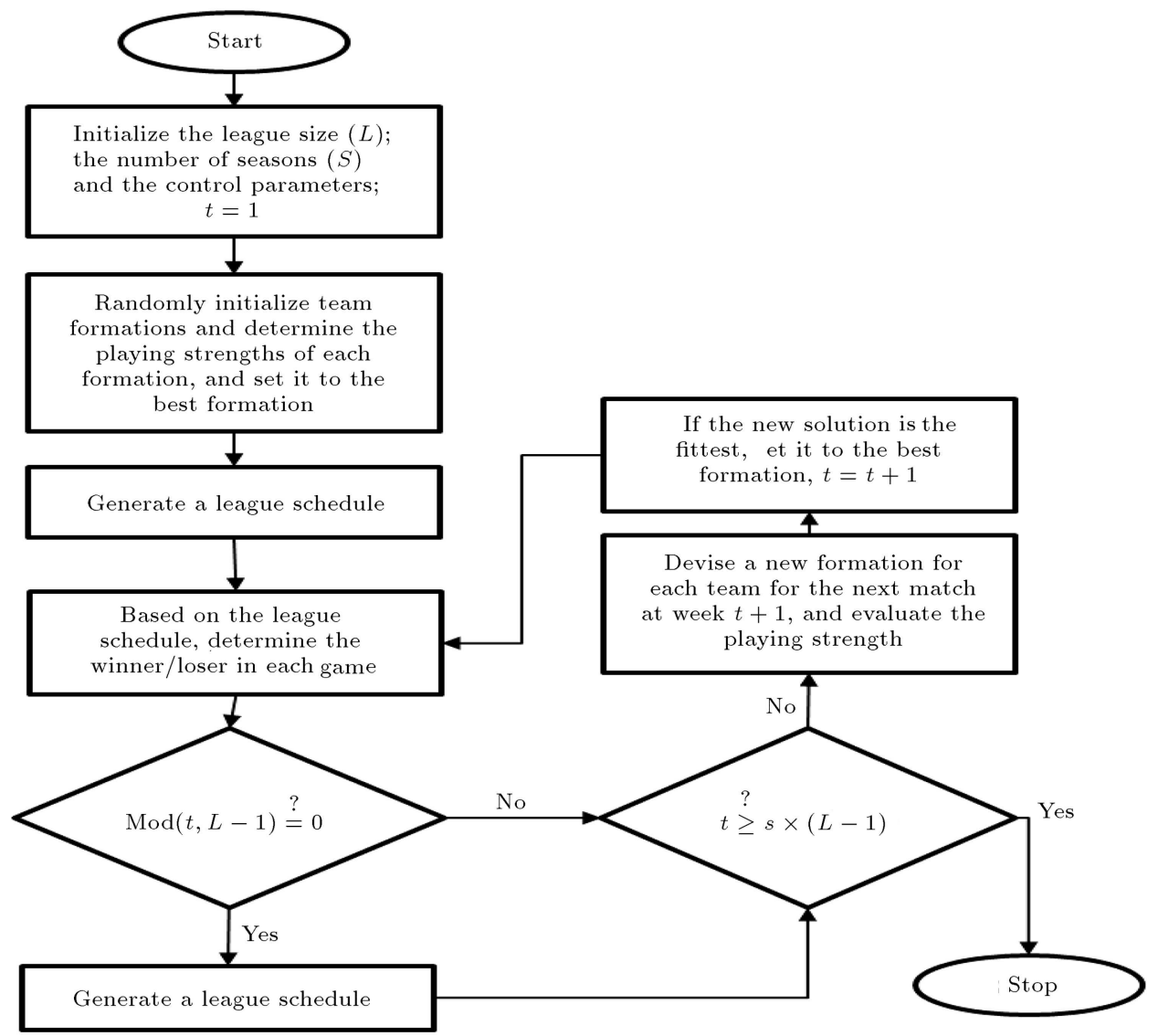

Figure 4. Flowchart of League Championship Algorithm (LCA).

\begin{tabular}{|l|l|l|l|l|l|l|l|l|}
\hline$k_{1, t}^{s}$ & $k_{2, t}^{s}$ & $k_{3, t}^{s}$ & $c_{1, t}^{s}$ & $c_{2, t}^{s}$ & $c_{3, t}^{s}$ & $y_{1, t}^{s}$ & $y_{2, t}^{s}$ & $y_{3, t}^{s}$ \\
\hline
\end{tabular}

Figure 5. Solution representation for the Multi-Period Portfolio Optimization (MPPO) problem.

construction of the scenario tree, we will introduce the parameters required to solve the MPPO model. As previously mentioned, scenario tree has been used only for prediction of one parameter, i.e., rate of return on risky assets $\left(l_{n, t}^{s}\right)$. Probabilities of all scenarios $\left(\varepsilon_{s}\right)$ are assumed to be equal for each problem. For example, if the MPPO model has 5 scenarios, $\varepsilon_{s}$ is equal to 0.2 for each scenario. Additionally, the value of transaction cost $\left(\gamma_{n, t}\right)$ is available directly from the market. With $l_{n, t}^{s}, \varepsilon_{s}$, and $\gamma_{n, t}$ as parameters of the MPPO problem, we can apply LCA to finding a solution that optimizes the objective function.

\subsubsection{Solution representation}

To run the algorithm, we introduce a new decision variable denoted by $k_{n, t}^{s}$. It is the proportion of asset wealth invested in the asset after rebalancing under several scenarios over the planning horizon equal to $x_{n, t}^{s} / w_{t}^{s}$. This percentage in each node must be one hundred percent for three used assets in this problem. If the amount of $k_{n, t}^{s}$ in each node is not equal to one hundred percent, we must normalize $k_{n, t}^{s}$ through Eq. (33).

$$
k_{n, t}^{s}=k_{n, t}^{s} / \sum_{n=1}^{3} k_{n, t}^{s} .
$$

The amounts of purchase and sell are two other decision variables in the implementation of LCA. Therefore, three sets of decision variables are used in each node for each asset and regarding $n$ assets, we have $3^{*} n$ decision variables in total in each node.

Accordingly, the solution (team in LCA) is represented by a vector comprising of three sets of variables: $k_{n, t}^{s}, c_{n, t}^{s}, y_{n, t}^{s}$, namely the amount of money for asset $n$, the amount of asset $n$ purchased, and the amount of asset $n$ sold, respectively (Figure 5 ).

The number of nodes in this algorithm is equal to:

no. of nodes $=[($ number of periods -1$)$

$$
\text { *number of scenarios] }+1
$$


and the total number of variables is $\left[9^{*}\right.$ number of nodes], which shows problem dimensions.

\subsubsection{Introduction to the diversification constraint in $L C A$ by penalty function}

LCA was originally introduced for solving unconstrained continuous problems. This algorithm can be used for solving portfolio diversification without constraints by adopting a solution representation that takes account of other restrictions. However, when diversification constraint (7) is applied, we need a technique to overcome the limitations of LCA as well. For this purpose, the penalty function method is used in this paper.

The search space of the constrained optimization problems consists of two types of points: feasible and infeasible. Feasible points satisfy all constraints, while in infeasible points, at least one of the constraints is violated. Penalty function technique solves the constrained optimization problem through a series of optimization problems without constraints. If the penalty is too large, minimizing algorithms usually fall into the trap of local minimum. On the other hand, if the penalty is too small, the algorithm can hardly detect feasible optimal solutions. Penalty functions commonly fall into two main groups: static and dynamic. Static penalty functions use fixed penalty values, while dynamic penalty functions adjust penalty values in the course of search. The objective function with penalty function $(F(x))$ is defined as follows:

$$
F(x)=f(x)+h(k) H(x), \quad x \in S \subset R^{n},
$$

where $f(x)$ is the objective function of the problem, $h(k)$ is the penalty value adjusted dynamically, $k$ is the current iteration of the algorithm, and $H(x)$ is a penalty function that can be defined as follows:

$$
H(x)=\sum_{i=1}^{m} \theta\left(q_{i}(x)\right) q_{i}(x)^{\gamma\left(q_{i}(x)\right)},
$$

where $q_{i}(x)=\max \left\{0, g_{i}(x)\right\}, i=1, \cdots, m$ is a function of constraints violation; $\theta\left(q_{i}(x)\right)$ is periodic assignment function; $\gamma\left(q_{i}(x)\right)$ is the power of penalty function; $g_{i}(x)$ is the amount of violation in the $i$ th constraint and $h(),. \theta($.$) , and \gamma($.$) are dependent functions.$

\section{Computational experiments and results}

In this section, the values of the parameter used for solving the problem are presented. Numerical experiments and their analyses are also presented for demonstrating efficiency of the proposed algorithm.

\subsection{Parameter setting}

Prior to the implementation of the LCA and optimization solver, historical data for the rates of return on risky assets have been extracted from 2001 to 2013 in yearly intervals. As already stated, S\&P 500 index and 10-year $\mathrm{T}$. bond are representatives of stock and bond. The other asset is called cash. Thus, we have three assets in total in this study. Also, the tested periods are 4 and 7 and the tested scenarios are 2, 5, 10, 20, and 50. Moreover, the rate of return on risky assets is predicted by VAR model and for cash, it is considered constant and equal to 0.12. Lower bound of diversification constraint is equal to $\ln (0, n)$ and it is considered equal to 0.6 in this study. Transaction cost is equal to 0.005 for stock and 0.001 for bond. These values are fixed for stock and bond in all periods and initial investment is intended to be equal to $10 \$$.

Furthermore, in LCA, the league size is set equal to 16 , probability of success equal to 0.001 , and the number of iterations for each problem equal to 12000 . $w_{1}$ and $w_{2}$ are also generated every time randomly between $[0,2]$. These values are chosen according to a pilot study of various instances. The parameter values that result in the best results have been selected for running the numerical experiments.

\subsection{Numerical experiments}

The value of $r_{n, t}^{s}$ has been estimated by using VAR model. For the sake of brevity, we only report in Tables 1 and 2 the results of $r_{n, t}^{s}$ for 10 scenarios and 7 periods. LCA and LINGO/Quadratic Solver have been run to maximize the objective functions corresponding to a series of $v$ s for each multi-period problem (QS will be used hereafter instead of LINGO/Quadratic Solver for the sake of brevity). In order to compare the performances of LCA and QS in statistical terms, Wilcoxon signed rank test has been conducted with 0.05 level of significance. It is worth noting that the output of QS is the same for 10 runs. The results reported in the column " $p$-value" show the probability that the medians of the two paired samples (objective values of LCA and QS) are equal. Entries in which the difference is significant are underlined.

\subsubsection{The MPPO problem without diversification constraint}

Tables 3-5 contain the results for problem sets with $v=0.1,0.5$, and 0.9 each having 10 problem instances. The first section in Tables 3-5 reports the problem number and the numbers of periods and scenarios. The second part reports the objective function and run time of QS for each problem instance. The third section reports the best, the worst, and the average objective function values obtained as well as their standard deviations; also, in this section, the average run times of the LCA algorithm for the problems with different periods and scenarios are presented without considering the diversification constraint. It should be noted that LCA has been executed 10 times for each 
Table 3. Results for the solutions of League Championship Algorithm (LCA) and LINGO/Quadratic Solver (QS) without diversification constraint $(\nu=0.1)$.

\begin{tabular}{|c|c|c|c|c|c|c|c|c|c|c|}
\hline \multirow[b]{2}{*}{$\begin{array}{l}\text { Problem } \\
\text { instance }\end{array}$} & \multirow[b]{2}{*}{ Period } & \multirow[b]{2}{*}{ Scenario } & \multicolumn{2}{|l|}{ QS } & \multicolumn{5}{|c|}{ LCA } & \multirow[b]{2}{*}{$p$-value } \\
\hline & & & Objective & $\begin{array}{c}\text { Time } \\
(\mathrm{s})\end{array}$ & Best & Worst & Average & $\begin{array}{l}\text { St. } \\
\text { dev. }\end{array}$ & $\begin{array}{c}\text { Avg. } \\
\text { time } \\
(\mathrm{s})\end{array}$ & \\
\hline 1 & 4 & 2 & 1.43887 & 0 & 1.74576 & 1.74576 & 1.74576 & 0 & 102 & $p<0.001$ \\
\hline 2 & 4 & 5 & 1.44721 & 0 & 1.75326 & 1.75323 & 1.75326 & 0.00002 & 159 & $p<0.001$ \\
\hline 3 & 4 & 10 & 1.45778 & 0 & 1.76002 & 1.76002 & 1.76002 & 0 & 291 & $p<0.001$ \\
\hline 4 & 4 & 20 & 1.46445 & 0 & 1.72431 & 1.72372 & 1.72401 & 0.00041 & 495 & $0.001<p<0.05$ \\
\hline 5 & 4 & 50 & 1.42680 & 0 & 1.70120 & 1.67211 & 1.68666 & 0.02057 & 1235 & $0.001<p<0.05$ \\
\hline 6 & 7 & 2 & 2.13763 & 0 & 2.70884 & 2.70881 & 2.70884 & 0.00002 & 159 & $p<0.001$ \\
\hline 7 & 7 & 5 & 2.14596 & 0 & 2.51742 & 2.51742 & 2.51742 & 0 & 275 & $p<0.001$ \\
\hline 8 & 7 & 10 & 2.15985 & 0 & 2.53098 & 2.53008 & 2.53053 & 0.00063 & 493 & $p<0.001$ \\
\hline 9 & 7 & 20 & 2.09303 & 0 & 2.58762 & 2.56560 & 2.57661 & 0.01557 & 934 & $p<0.001$ \\
\hline 10 & 7 & 50 & 1.99217 & 1 & 2.20304 & 2.19539 & 2.19922 & 0.00540 & 2299 & $0.02<p<0.05$ \\
\hline
\end{tabular}

Table 4. Results for the solutions of League Championship Algorithm (LCA) and LINGO/Quadratic Solver (QS) without diversification constraint $(\nu=0.5)$.

\begin{tabular}{|c|c|c|c|c|c|c|c|c|c|c|}
\hline \multirow[b]{2}{*}{$\begin{array}{l}\text { Problem } \\
\text { instance }\end{array}$} & \multirow[b]{2}{*}{ Period } & \multirow[b]{2}{*}{ Scenario } & \multicolumn{2}{|l|}{ QS } & \multicolumn{5}{|c|}{ LCA } & \multirow[b]{2}{*}{$p$-value } \\
\hline & & & Objective & $\begin{array}{c}\text { Time } \\
(\mathrm{s})\end{array}$ & Best & Worst & Average & $\begin{array}{l}\text { St. } \\
\text { dev. }\end{array}$ & $\begin{array}{c}\text { Avg. } \\
\text { time } \\
(\mathrm{s})\end{array}$ & \\
\hline 1 & 4 & 2 & 7.305492 & 0 & 8.78439 & 8.78439 & 8.78439 & 0 & 102 & $0.001<p<0.05$ \\
\hline 2 & 4 & 5 & 7.367428 & 0 & 8.91260 & 8.91260 & 8.91260 & 0 & 164 & $0.001<p<0.05$ \\
\hline 3 & 4 & 10 & 7.456014 & 0 & 8.91795 & 8.91791 & 8.91793 & 0.00002 & 280 & $0.001<p<0.05$ \\
\hline 4 & 4 & 20 & 7.499922 & 0 & 8.79990 & 8.79824 & 8.79907 & 0.00117 & 503 & $0.001<p<0.05$ \\
\hline 5 & 4 & 50 & 7.488729 & 0 & 8.78739 & 8.76413 & 8.77576 & 0.01644 & 1169 & $0.001<p<0.05$ \\
\hline 6 & 7 & 2 & 10.79928 & 0 & 13.59977 & 13.59977 & 13.59977 & 0 & 152 & $p<0.001$ \\
\hline 7 & 7 & 5 & 11.11813 & 0 & 12.94266 & 12.94123 & 12.94194 & 0.00101 & 345 & $p<0.001$ \\
\hline 8 & 7 & 10 & 11.33397 & 0 & 13.10980 & 13.10856 & 13.10918 & 0.00087 & 484 & $p<0.001$ \\
\hline 9 & 7 & 20 & 11.20750 & 0 & 14.09058 & 13.72032 & 13.90545 & 0.26181 & 1114 & $p<0.001$ \\
\hline 10 & 7 & 50 & 10.95789 & 1 & 12.53980 & 12.47203 & 12.50591 & 0.04792 & 2298 & $p<0.001$ \\
\hline
\end{tabular}

Table 5. Results for the solutions of League Championship Algorithm (LCA) and LINGO/Quadratic Solver (QS) without diversification constraint $(\nu=0.9)$.

\begin{tabular}{|c|c|c|c|c|c|c|c|c|c|c|}
\hline \multirow[b]{2}{*}{$\begin{array}{l}\text { Problem } \\
\text { instance }\end{array}$} & \multirow[b]{2}{*}{ Period } & \multirow[b]{2}{*}{ Scenario } & \multicolumn{2}{|l|}{ QS } & \multicolumn{5}{|c|}{ LCA } & \multirow[b]{2}{*}{$p$-value } \\
\hline & & & Objective & $\begin{array}{c}\text { Time } \\
(\mathrm{s})\end{array}$ & Best & Worst & Average & $\begin{array}{l}\text { St. } \\
\text { dev. }\end{array}$ & $\begin{array}{c}\text { Avg. } \\
\text { time } \\
(\mathrm{s})\end{array}$ & \\
\hline 1 & 4 & 2 & 13.58976 & 0 & 15.91781 & 15.91781 & 15.91781 & 0 & 91 & $0.001<p<0.05$ \\
\hline 2 & 4 & 5 & 13.56771 & 0 & 16.17535 & 16.17535 & 16.17535 & 0 & 171 & $0.001<p<0.05$ \\
\hline 3 & 4 & 10 & 14.04425 & 0 & 16.26282 & 16.26227 & 16.26255 & 0.00038 & 285 & $0.001<p<0.05$ \\
\hline 4 & 4 & 20 & 14.05894 & 0 & 16.02792 & 16.02672 & 16.02732 & 0.00084 & 520 & $0.001<p<0.05$ \\
\hline 5 & 4 & 50 & 13.97634 & 0 & 15.96406 & 15.94856 & 15.95631 & 0.01096 & 1214 & $0.001<p<0.05$ \\
\hline 6 & 7 & 2 & 20.76308 & 0 & 25.37959 & 25.37959 & 25.37959 & 0 & 147 & $p<0.001$ \\
\hline 7 & 7 & 5 & 21.20740 & 0 & 25.27803 & 25.27791 & 25.27797 & 0.00008 & 292 & $p<0.001$ \\
\hline 8 & 7 & 10 & 21.67977 & 0 & 25.27948 & 25.25263 & 25.56605 & 0.01898 & 511 & $p<0.001$ \\
\hline 9 & 7 & 20 & 21.48841 & 0 & 26.56687 & 26.48416 & 26.52551 & 0.05848 & 929 & $p<0.001$ \\
\hline 10 & 7 & 50 & 21.50172 & 1 & 23.99405 & 23.86318 & 23.92862 & 0.09253 & 2292 & $0.001<p<0.05$ \\
\hline
\end{tabular}


problem instance to obtain the average performance in terms of the objective function and run time.

By means of Tables 3-5, the QS and LCA results can be compared in terms of the objective function obtained and the run time. Specifically, it can be observed that the best, the worst, and the average objective function values obtained by the LCA are better than those by the QS in all problem instances. This shows the superior performance of LCA. However, the run time of QS, which is less than one second, is considerably low in comparison with the run time of LCA, which ranges between 1.5 and 39 minutes. The column containing LCA times also shows that in a fixed number of periods, the run time is sensitive to the number of scenarios. The $p$-values for instances show that the difference is statistically significant most of the times ( 29 instances out of 30 for all values of $v$ ).

\subsection{Analysis of the results of $L C A$ and $Q S$}

In this section, the gap between the results of QS and LCA is analyzed using Eq. (36):

$$
\text { Gap }=\frac{\text { obj. value of } L C A-\text { obj. value of } Q S}{\text { obj. value of } L C A} .
$$

\subsubsection{The MPPO problem with diversification constraint}

Tables 6-8 report the results for the MMPO problems by considering the diversification constraint as described previously. As can be seen in all tables, results of LCA are better than those of QS in terms of

Table 6. Results for the solutions of League Championship Algorithm (LCA) and LINGO/Quadratic Solver (QS) with diversification constraint $(\nu=0.1)$.

\begin{tabular}{|c|c|c|c|c|c|c|c|c|c|c|}
\hline \multirow[b]{2}{*}{$\begin{array}{l}\text { Problem } \\
\text { instance }\end{array}$} & \multirow[b]{2}{*}{ Period } & \multirow[b]{2}{*}{ Scenario } & \multicolumn{2}{|l|}{ QS } & \multicolumn{5}{|c|}{ LCA } & \multirow[b]{2}{*}{$p$-value } \\
\hline & & & Objective & $\begin{array}{c}\text { Time } \\
(\mathrm{s})\end{array}$ & Best & Worst & Average & $\begin{array}{l}\text { St. } \\
\text { dev. }\end{array}$ & $\begin{array}{c}\text { Avg. } \\
\text { time } \\
(\mathrm{s})\end{array}$ & \\
\hline 1 & 4 & 2 & 1.400343 & 0 & 1.62622 & 1.62617 & 1.62619 & 0.00003 & 122 & $p<0.001$ \\
\hline 2 & 4 & 5 & 1.408662 & 0 & 1.62981 & 1.62960 & 1.62971 & 0.00014 & 203 & $p<0.001$ \\
\hline 3 & 4 & 10 & 1.416495 & 0 & 1.62291 & 1.62237 & 1.62264 & 0.00038 & 349 & $p<0.001$ \\
\hline 4 & 4 & 20 & 1.419273 & 5 & 1.59788 & 1.59347 & 1.59568 & 0.00311 & 465 & $0.001<p<0.05$ \\
\hline 5 & 4 & 50 & 1.392164 & 14 & 1.56867 & 1.56821 & 1.56844 & 0.00032 & 1342 & $0.001<p<0.05$ \\
\hline 6 & 7 & 2 & 1.998293 & 0 & 2.3705 & 2.37037 & 2.37044 & 0.00009 & 142 & $p<0.001$ \\
\hline 7 & 7 & 5 & 2.006627 & 0 & 2.22721 & 2.22280 & 2.22500 & 0.00311 & 270 & $p<0.001$ \\
\hline 8 & 7 & 10 & 2.020516 & 0 & 2.23442 & 2.21470 & 2.22456 & 0.01394 & 466 & $p<0.001$ \\
\hline 9 & 7 & 20 & 1.966331 & 4 & 2.28229 & 2.27927 & 2.228078 & 0.00213 & 911 & $p<0.001$ \\
\hline 10 & 7 & 50 & 1.883260 & 29 & 2.07195 & 2.05836 & 2.06516 & 0.00961 & 2201 & $0.02<p<0.05$ \\
\hline
\end{tabular}

Table 7. Results for the solutions of League Championship Algorithm (LCA) and LINGO/Quadratic Solver (QS) with diversification constraint $(\nu=0.5)$.

\begin{tabular}{|c|c|c|c|c|c|c|c|c|c|c|}
\hline \multirow[b]{2}{*}{$\begin{array}{l}\text { Problem } \\
\text { instance }\end{array}$} & \multirow[b]{2}{*}{ Period } & \multirow[b]{2}{*}{ Scenario } & \multicolumn{2}{|l|}{ QS } & \multicolumn{5}{|c|}{ LCA } & \multirow[b]{2}{*}{$p$-value } \\
\hline & & & Objective & $\begin{array}{l}\text { Time } \\
(\mathrm{s})\end{array}$ & Best & Worst & Average & $\begin{array}{l}\text { St. } \\
\text { dev. }\end{array}$ & $\begin{array}{c}\text { Avg. } \\
\text { time } \\
(\mathrm{s})\end{array}$ & \\
\hline 1 & 4 & 2 & 7.112826 & 0 & 8.14475 & 8.14404 & 8.14439 & 0.00050 & 120 & $0.001<p<0.05$ \\
\hline 2 & 4 & 5 & 7.155470 & 0 & 8.18213 & 8.17792 & 8.18003 & 0.00297 & 206 & $0.001<p<0.05$ \\
\hline 3 & 4 & 10 & 7.230205 & 1 & 8.19920 & 8.19749 & 8.19835 & 0.00120 & 340 & $0.001<p<0.05$ \\
\hline 4 & 4 & 20 & 7.257485 & 2 & 8.13284 & 8.10920 & 8.120102 & 0.01671 & 452 & $0.001<p<0.05$ \\
\hline 5 & 4 & 50 & 7.242559 & 11 & 8.09869 & 8.08431 & 8.09150 & 0.01016 & 1420 & $0.001<p<0.05$ \\
\hline 6 & 7 & 2 & 10.10258 & 0 & 11.91485 & 11.90585 & 11.91035 & 0.00636 & 136 & $0.001<p<0.05$ \\
\hline 7 & 7 & 5 & 10.38395 & 0 & 11.51199 & 11.50032 & 11.50616 & 0.00825 & 271 & $0.001<p<0.05$ \\
\hline 8 & 7 & 10 & 10.54530 & 0 & 11.56264 & 11.62272 & 11.59268 & 0.04248 & 493 & $0.001<p<0.05$ \\
\hline 9 & 7 & 20 & 10.42279 & 4 & 12.13665 & 12.06563 & 12.10114 & 0.05021 & 909 & $p<0.001$ \\
\hline 10 & 7 & 50 & 10.26006 & 79 & 11.34594 & 11.34288 & 11.34441 & 0.00216 & 2210 & $0.001<p<0.05$ \\
\hline
\end{tabular}


Table 8. Results for the solutions of League Championship Algorithm (LCA) and LINGO/Quadratic Solver (QS) with diversification constraint $(\nu=0.9)$.

\begin{tabular}{|c|c|c|c|c|c|c|c|c|c|c|}
\hline \multirow[b]{2}{*}{$\begin{array}{l}\text { Problem } \\
\text { instance }\end{array}$} & \multirow[b]{2}{*}{ Period } & \multirow[b]{2}{*}{ Scenario } & \multicolumn{2}{|l|}{ QS } & \multicolumn{5}{|c|}{ LCA } & \multirow[b]{2}{*}{$p$-value } \\
\hline & & & Objective & $\begin{array}{l}\text { Time } \\
(\mathrm{s})\end{array}$ & Best & Worst & Average & $\begin{array}{l}\text { St. } \\
\text { dev. }\end{array}$ & $\begin{array}{l}\text { Avg. } \\
\text { time } \\
(\mathrm{s})\end{array}$ & \\
\hline 1 & 4 & 2 & 13.10515 & 0 & 14.6628 & 14.6618 & 14.66230 & 0.00070 & 121 & $0.001<p<0.05$ \\
\hline 2 & 4 & 5 & 13.07473 & 0 & 14.78895 & 14.78712 & 14.78803 & 0.00129 & 205 & $0.001<p<0.05$ \\
\hline 3 & 4 & 10 & 13.47653 & 0 & 14.93468 & 14.93047 & 14.93257 & 0.00297 & 333 & $0.001<p<0.05$ \\
\hline 4 & 4 & 20 & 13.48377 & 1 & 14.789 & 14.77685 & 14.78293 & 0.00859 & 466 & $0.001<p<0.05$ \\
\hline 5 & 4 & 50 & 13.39829 & 9 & 14.71673 & 14.71132 & 14.71403 & 0.00383 & 1450 & $0.001<p<0.05$ \\
\hline 6 & 7 & 2 & 19.17639 & 0 & 22.34525 & 22.34504 & 22.34515 & 0.00015 & 138 & $p<0.001$ \\
\hline 7 & 7 & 5 & 19.50183 & 0 & 22.07479 & 22.05991 & 22.06735 & 0.01052 & 285 & $p<0.001$ \\
\hline 8 & 7 & 10 & 19.85209 & 0 & 22.08005 & 22.05852 & 22.06929 & 0.01522 & 494 & $p<0.001$ \\
\hline 9 & 7 & 20 & 19.66106 & 3 & 22.81577 & 22.78076 & 22.79827 & 0.02475 & 897 & $p<0.001$ \\
\hline 10 & 7 & 50 & 19.67796 & 29 & 21.54311 & 21.53436 & 21.53874 & 0.00618 & 2240 & $p<0.001$ \\
\hline
\end{tabular}

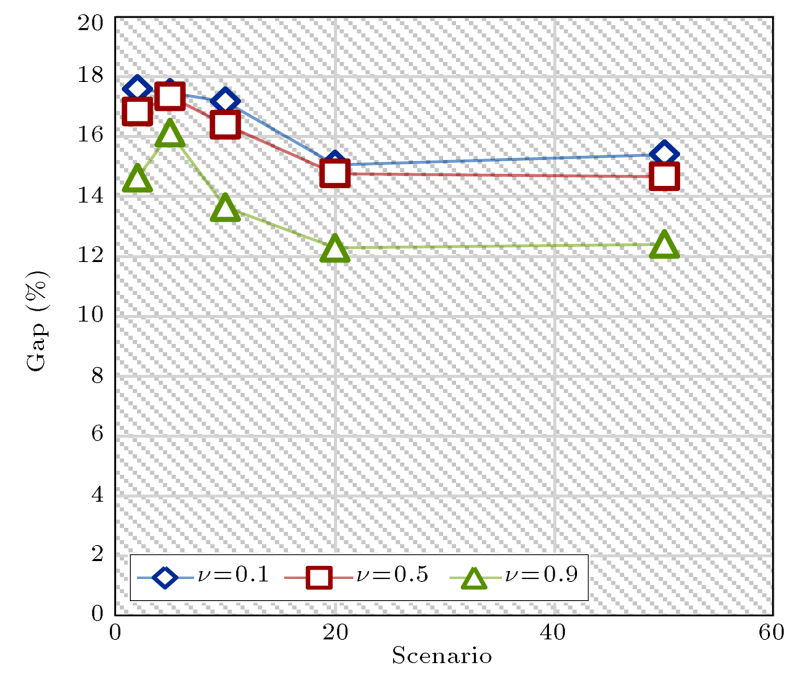

Figure 6. Gap of solutions of League Championship Algorithm (LCA) and LINGO/Quadratic Solver (QS) output without diversification constraint for 4 periods.

objective function values obtained for all periods and scenarios. The run time of QS is less than 1.5 minutes while the run time of LCA ranges between 2 and 38 minutes. As expected, the run time increases when the number of scenarios increases for a fixed number of periods. In terms of the objective function values, the difference between LCA and QS is significant in most of the instances (29 instances out of 30 for all values of $v$ ).

Due to the nonlinearities in the MPPO problem, the solutions to the original problem with and without the diversification constraint (Shannon entropy) are local. As a result, the solution to the problem that is solved by LCA meta-heuristic algorithm may possibly be better than the result of QS. Figures 6 and 7 show the gap between the results of QS and LCA without diversification constraint for 4-period and 7-

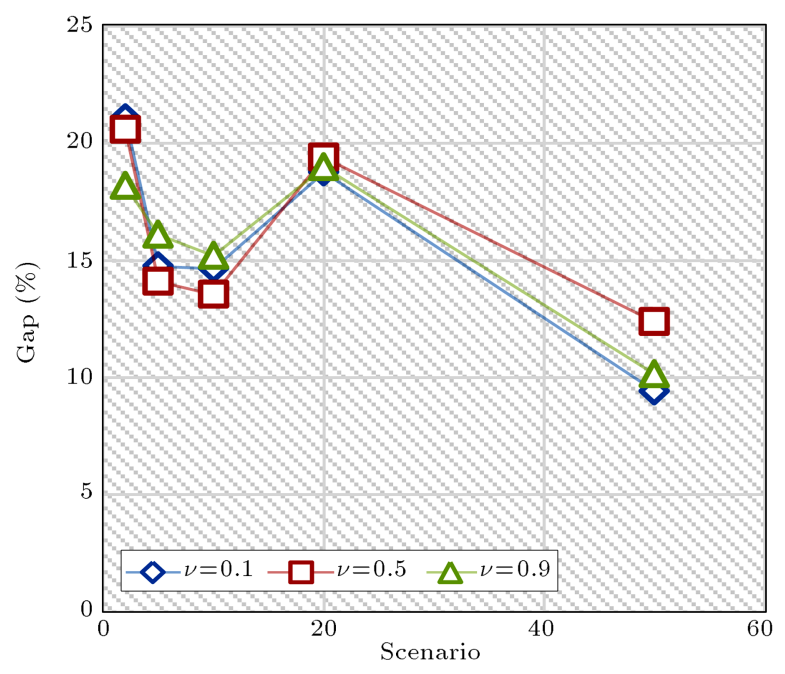

Figure 7. Gap of solutions of League Championship Algorithm (LCA) and LINGO/Quadratic Solver (QS) output without diversification constraint for 7 periods.

period cases, respectively, under 2, 5, 10, 20, and 50 scenarios. For the case of 4 periods (Figure 6), gaps vary between 12 and 18 percent and there are similar trends for different values of $\nu$.

For the case of 7 periods (Figure 7 ), the gap is relatively wider and between 9 and 21 percent for different scenarios and $\nu$ s.

Moreover, Figures 8 and 9 report similar results for the problem with diversification constraint. Figure 8 shows the gap for the 4-period case, which is between 8 to 14 percent for all scenarios and $v$ s. The gap for the 7 -period case is between 8 to 16 percent, as Figure 9 demonstrates.

As Figures 7-9 demonstrate, all of the results of LCA are better than the output of QS in terms of the objective function values (between 8 to 20 percent). 


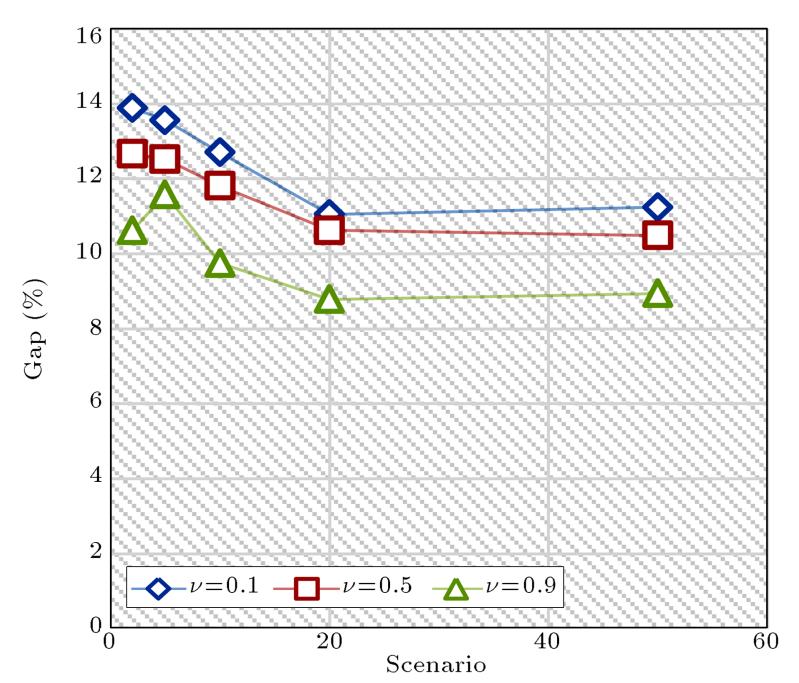

Figure 8. Gap of solutions of League Championship Algorithm (LCA) and LINGO/Quadratic Solver (QS) output with diversification constraint for 4 periods.

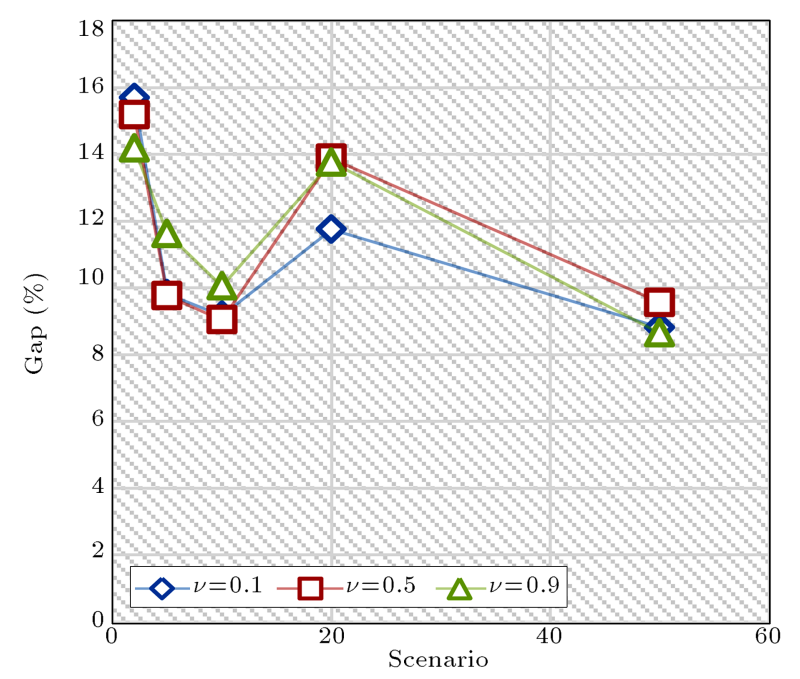

Figure 9. Gap of solutions of League Championship Algorithm (LCA) and LINGO/Quadratic Solver (QS) output with diversification constraint for 7 periods.

In order to observe the behavior of LCA in both cases of with and without diversification constraint, the convergence diagram is illustrated in Figure 10 for instance 1 with $v=0.9$ in 1000 iterations.

\section{Conclusions and future research}

In this paper, Vector Auto-Regression (VAR) has been used to model the return on risky assets. VAR works based on historical data. Alternatively, other methods use economic indicators such as inflation, interest rates, and market indices. It is important to note that using economic indicators depends on the knowledge about the future of the economy and economic variables under study. As we know, the future of the market is complex to predict due to the impact of macroeconomic

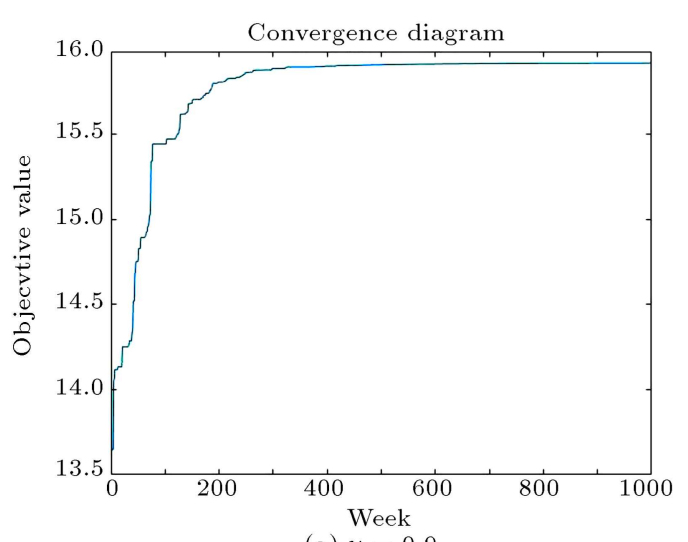

(a) $\nu=0.9$

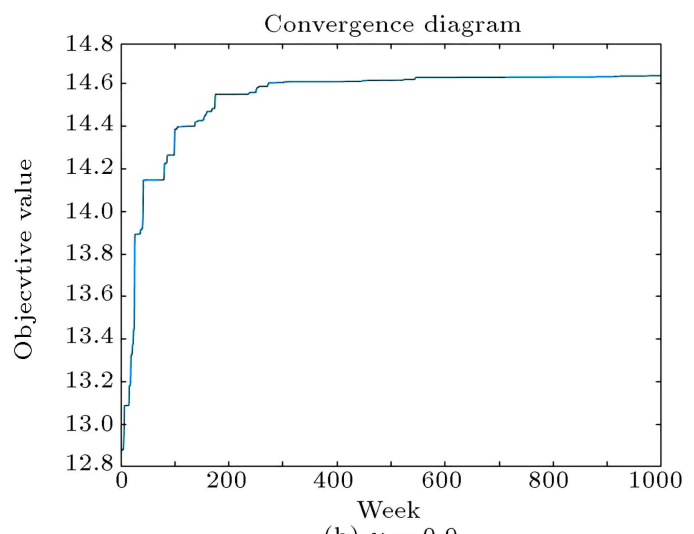

(b) $\nu=0.9$

Figure 10. Convergence diagrams for instance 1: (a) Without and (b) with diversification constraint.

variables. Therefore, based on historical data from 2000 to 2013 for stocks and bonds, return on risky assets was modeled. Scenarios made for the stocks and bonds were $2,5,10,20$, and 50 with periods of 4 and 7 years. After scenario generation, the upper-bound model was developed, which had a single scenario and was convenient to solve in comparison with the mathematical model of the problem. MPPO model was solved using LINGO/Quadratic Solver (QS) and a new meta-heuristic called LCA. Applying this algorithm to multi-period optimization problem was due to nonlinear and complicated nature of the problem. The results of LCA for 4 and 7 periods and all scenarios were better than the output of QS (between 8 to 20 percent) in terms of the objective function values obtained. The difference in the objective functions obtained was statistically significant in most of the instances. This proved the effectiveness of the LCA proposed for the problem.

The current research sought to maximize mean variance objective function. There are other objective functions such as mean variance skewness and Von Neumann-Morgenstern expected utility of wealth that can be optimized instead. Additionally, the efficiency of other recently proposed meta-heuristic algorithms such as OIO $[44,45]$ may be investigated in the future 
research. The extension of our model to the continuous time case is also worth analyzing, considering the fact that many investors change their portfolios continuously rather than at discrete points in time. Taking account of liquidity, which is one of the main concerns for investors in making a portfolio decision, is another issue to investigate.

\section{References}

1. Markowitz, H. "Portfolio selection", The Journal of Finance, 7(1), pp. 77-91 (1952).

2. Yoshimoto, A. "The mean-variance approach to portfolio optimization subject to transaction costs", Journal of the Operations Research Society of Japan, 39(1), pp. 99-117 (1996).

3. Best, M.J. and Hlouskova, J. "Portfolio selection and transactions costs", Computational Optimization and Applications, 24(1), pp. 95-116 (2003).

4. Liu, S., Wang, S.Y., and Qiu, W. "Mean-varianceskewness model for portfolio selection with transaction costs", International Journal of Systems Science, 34(4), pp. 255-262 (2010).

5. Favaretto, D. "On the existence of solutions to the quadratic mixed-integer mean-variance portfolio selection problem", European Journal of Operational Research, 176(3), pp. 1947-1960 (2007).

6. Mulvey, J.M. and Shetty, B. "Financial planning via multi-stage stochastic optimization", Computers \& Operations Research, 31(1), pp. 1-20 (2004).

7. Carino, D.R., Myers, D.H., and Ziemba, W.T. "Concepts, technical issues, and uses of the Russell-Yasuda Kasai financial planning model", Operations Research, 46(4), pp. 450-462 (1998).

8. Ertenlice, O. and Kalayci, C.B. "A survey of swarm intelligence for portfolio optimization: Algorithms and applications", Swarm and Evolutionary Computation, 39, pp. 36-52 (2018).

9. Deng, G.-F., Lin, W.-T., and Lo, C.-C. "Markowitzbased portfolio selection with cardinality constraints using improved particle swarm optimization", Expert Systems with Applications, 39, pp. 4558-4566 (2012).

10. Woodside-Oriakhi, M., Lucas, C., and Beasley, J.E. "Heuristic algorithms for the cardinality constrained efficient frontier", European Journal of Operational Research, 213, pp. 538-550 (2011).

11. Baykasoğlu, A., Yunusoglu, M.G., and Özsoydan, F.B. "A GRASP based solution approach to solve cardinality constrained portfolio optimization problems", Computers \& Industrial Engineering, 90, pp. 339-351 (2015).

12. Kalayci, C.B., Ertenlice, O., Akyer, H., and Aygoren, H. "An artificial bee colony algorithm with feasibility enforcement and infeasibility toleration procedures for cardinality constrained portfolio optimization", Expert Systems with Applications, 85, pp. 61-75 (2017).
13. Bradley, S.P. and Crane, D.B. "A dynamic model for bond portfolio management", Management Science, 19(2), pp. 139-151 (1972).

14. Kallberg, J.G. and Ziemba, W.T. "Comparison of alternative utility functions in portfolio selection problems", Management Science, 29(11), pp. 1257-1276 (1983).

15. Mulvey, J.M. and Vladimirou, H. "Stochastic network optimization models for investment planning", Annals of Operations Research, 20(1), pp. 187-217 (1989).

16. Wei, S.Z. and Ye, Z.X. "Multi-period optimization portfolio with bankruptcy control in stochastic market", Applied Mathematics and Computation, 186(1), pp. 414-425 (2007).

17. Bertsimas, D. and Pachamanova, D. "Robust multiperiod portfolio management in the presence of transaction costs", Computers \& Operations Research, 35(1), pp. 3-17 (2008).

18. Çakmak, U. and Özekici, S. "Portfolio optimization in stochastic markets", Mathematical Methods of Operations Research, 63(1), pp. 151-168 (2006).

19. Li, D. and Ng, W.L. "Optimal dynamic portfolio selection: Multiperiod mean-variance formulation", Mathematical Finance, 10(3), pp. 387-406 (2000).

20. Zhu, S.S., Li, D., and Wang, S.Y. "Risk control over bankruptcy in dynamic portfolio selection: A generalized mean-variance formulation", Automatic Control, IEEE Transactions on, 49(3), pp. 447-457 (2004).

21. Pınar, M.Ç. "Robust scenario optimization based on downside-risk measure for multi-period portfolio selection", OR Spectrum, 29(2), pp. 295-309 (2007).

22. Zhang, W.G., Liu, Y.J., and Xu, W.J. "A possibilistic mean-semivariance-entropy model for multi-period portfolio selection with transaction costs", European Journal of Operational Research, 222(2), pp. 341-349 (2012).

23. Fang, Y., Lai, K.K., and Wang, S.Y. "Portfolio rebalancing model with transaction costs based on fuzzy decision theory", European Journal of Operational Research, 175(2), pp. 879-893 (2006).

24. Sadjadi, S.J., Seyedhosseini, S.M., and Hassanlou, K. "Fuzzy multi period portfolio selection with different rates for borrowing and lending", Applied Soft Computing, 11(4), pp. 3821-3826 (2011).

25. Zhang, P., and Zhang, W.G. "Multiperiod mean absolute deviation fuzzy portfolio selection model with risk control and cardinality constraints", Fuzzy Sets and Systems, 255, pp. 74-91 (2014). 
26. Yao, H., Li, Z., and Li, D. "Multi-period meanvariance portfolio selection with stochastic interest rate and uncontrollable liability", European Journal of Operational Research, 252(3), pp. 837-851 (2016).

27. Berger, A.J., Glover, F., and Mulvey, J.M. "Solving global optimization problems in long-term financial planning", Statistics and Operation Research Technical Report, Princeton University (1995).

28. Berger, A.J. and Mulvey, J.M. "Integrative risk management for individual investors", Worldwide Asset and Liability Modeling, Cambridge University Press (1996).

29. Chan, M.C., Wong, C.C., Cheung, B.K.S., and Tang, G.N. "Genetic algorithms in multi-stage asset allocation system", In Systems, Man and Cybernetics, 2002 IEEE International Conference on, 3, p. 6, IEEE (October, 2002).

30. Sun, J., Fang, W., Wu, X., Lai, C.H., and Xu, W. "Solving the multi-stage portfolio optimization problem with a novel particle swarm optimization", Expert Systems with Applications, 38(6), pp. 67276735 (2011).

31. Yan, W., Miao, R., and Li, S. "Multi-period semivariance portfolio selection: Model and numerical solution", Applied Mathematics and Computation, 194(1), pp. 128-134 (2007).

32. Zhang, X., Zhang, W., and Xiao, W. "Multi-period portfolio optimization under possibility measures", Economic Modelling, 35, pp. 401-408 (2013).

33. Liu, Y.J., Zhang, W.G., and Zhang, Q. "Credibilistic multi-period portfolio optimization model with bankruptcy control and affine recourse", Applied Soft Computing, 38, pp. 890-906 (2016).

34. Liu, J., Jin, X., Wang, T., and Yuan, Y. "Robust multi-period portfolio model based on prospect theory and ALMV-PSO algorithm", Expert Systems with Applications, 42(20), pp. 7252-7262 (2015).

35. Wang, B., Li, Y., and Watada, J. "Multi-period portfolio selection with dynamic risk/expected-return level under fuzzy random uncertainty", Information Sciences, 385-386, pp. 1-18 (2017).

36. Li, B., Zhu, Y., Sun, Y., Aw, G., and Teo, K.L. "Multiperiod portfolio selection problem under uncertain environment with bankruptcy constraint", Applied Mathematical Modelling, 56, pp. 539-550 (2018).

37. Zhao, Y., and Ziemba, W.T.A. "Stochastic programming model using an endogenously determined worst case risk measure for dynamic asset allocation", Mathematical Programming, 89(2), pp. 293-309 (2001).

38. Jacobson, H.I. "The maximum variance of restricted unimodal distributions", The Annals of Mathematical Statistics, 40(5), pp. 1746-1752 (1969).
39. Husseinzadeh Kashan, A. "An efficient algorithm for constrained global optimization and application to mechanical engineering design: League championship algorithm (LCA)", Computer-Aided Design, 43(12), pp. 1769-1792 (2011).

40. Husseinzadeh Kashan, A. "League championship algorithm: a new algorithm for numerical function optimization", In 2009 International Conference of Soft Computing and Pattern Recognition, pp. 43-48, IEEE (December, 2009).

41. Husseinzadeh Kashan, A. "League Championship Algorithm (LCA): An algorithm for global optimization inspired by sport championships", Applied Soft Computing, 16, pp. 171-200 (2014).

42. Alimoradi, M.R. and Husseinzadeh Kashan, A. "A league championship algorithm equipped with network structure and backward Q-learning for extracting stock trading rules", Applied Soft Computing, 68, pp. 478493 (2018).

43. Husseinzadeh Kashan, A., Abbasi-Pooya, A., and Karimiyan, S. "A rig-based formulation and a league championship algorithm for helicopter routing in offshore transportation", Proceedings of the 2nd International Conference on Data Engineering and Communication Technology: ICDECT 2017, Volume 828 of Advances in Intelligent Systems and Computing (2017).

44. Husseinzadeh Kashan, A. "A new metaheuristic for optimization: optics inspired optimization (OIO)", Computers \& Operations Research, 55, pp. 99-125 (2015).

45. Husseinzadeh Kashan, A. "An effective algorithm for constrained optimization based on optics inspired optimization (OIO)", Computer-Aided Design, 63, pp. 52-71 (2015).

\section{Biographies}

Ali Husseinzadeh Kashan holds degrees in Industrial Engineering from Amirkabir University of Technology (Tehran Poly-Technique), Iran. He worked as a postdoctoral research fellow in the Department of Industrial Engineering and Management Systems with the financial support of Iran National Elite foundations. Dr. Kashan is currently an Associate Professor in the Faculty of Industrial and Systems Engineering, Tarbiat Modares University, and has been active in applied optimization research field since 2004 . His research focuses on modeling and solving hard combinatorial optimization problems in areas such as logistics and supply networks, revenue management and pricing, resource scheduling, grouping problems, financial engineering, etc. He has introduced several intelligent optimization procedures inspired by different phenomena, such as League Championship Algorithm (LCA), Optics Inspired Optimization (OIO), FindFix-Finish-Exploit-Analyze (F3EA) metaheuristic algorithm, and Grouping Evolution Strategies (GES), 
as solution methodologies for real-world engineering design problems. Dr. Kashan has published over 70 peer-reviewed journal and conference papers, and has served several outstanding journals, such as IEEE Transactions on Evolutionary Computations, Omega, Computers \& Operations Research, Journal of the Operational Research Society, Computers \& Industrial Engineering, International Journal of Production Research, Information Sciences, Applied Soft Computing, Ecological Informatics, Engineering Optimization, Optimal Control and Applications, etc. as a referee. He has received several awards from Iran National Elite Foundation and in 2016, he was honored by the Academy of Sciences of Iran as the "Outstanding Young Scientist of Industrial Engineering."

Mohammad Eyvazi received his BSc degree in Industrial Engineering from University of Tabriz in 2011 and his MSc degree in Financial Engineering from Tarbiat Modares University in 2014. His research interest is portfolio optimization.

Amin Abbasi-Pooya received his BSc and MSc degrees in Industrial Engineering from Yazd University and Tarbiat Modares University, respectively. His research interest is applied operations research. 